\title{
LOW SPEED IMPACT TEST OF HEAVY DUTY BUMPER
}

\author{
V. K. V. S. KRISHNAM RAJU ${ }^{1}$, G. V. R. SESHAGIRI RAO ${ }^{2} \&$ SURYAPRAKASH $^{3}$ \\ ${ }^{\text {I}}$ Associate Professor, Department of Mechanical Engineering, Institute of Aeronautical Engineering, \\ Dundigal, Hyderabad, India
}

${ }^{2}$ Professor, Department of Mechanical Engineering, Institute of Aeronautical Engineering, Dundigal, Hyderabad, India

${ }^{3}$ Assistant Professor, Department of Mechanical Engineering, MLR Institute of Technology, Dundigal, Hyderabad, India

\begin{abstract}
Bumpers are basic parts introduced at the front and backsides of a vehicle to secure, the auto body, frill, and travellers amid low speed impacts. A bumper is a shield made of steel, aluminium, elastic, or plastic that is mounted on the front and back of a traveller auto. Bumpers are for the most part made out of bars, stays, safeguards and sash. At the point when a low speed impact happens, the guard framework assimilates the stun to secure or decrease harm to the auto. A few guards utilize vitality safeguards or sections and others are made with froth padding material. An automotive bumper reduces damage by absorbing kinetic energy so that the load transmitted to the body frame is minimized. As a result, bumper systems have evolved into complex engineered systems. The front bumper is the part, during a front crash that has contact with the opponent vehicle. The structural requirements of the bumper are very multifaceted. In component tests at the drop tower facility or in the crash test facility, which reflect different crash repair tests, flexural rigidity of the bumper as well as the deformation force level of the absorption elements can be determined. On servo-hydraulic test benches these tests can be accomplished quasi-statically.
\end{abstract}

KEYWORDS: Bumper, Impact Test \& Solver L-S dyna

Received: Feb 28, 2018; Accepted: Mar 21, 2018; Published: Apr 12, 2018; Paper Id.: IJMPERDAPR2018164

\section{INTRODUCTION}

A car bumper is a front part of the car that covers the car's chassis. The cover of the car bumper called fascia. A car's guard is the front-most or raise most part, apparently intended to enable the auto to maintain an effect without harm to the vehicle's wellbeing frameworks. They are not equipped for decreasing damage to vehicle tenants in rapid effects, however are progressively being intended to alleviate damage to people on foot struck via autos. Front and back guards ended up standard hardware on all autos in 1925. What were then basic metal pillars appended to the front and back of an auto have advanced into complex, built segments that are indispensable to the insurance of the vehicle in low-speed crashes. When a vehicle involves the low speed accident, the bumper system will absorbs the shock or force which will help in preventing the vehicle from serious damage. In certain type of bumper systems, the energy absorber or brackets are used while others used foam cushioning materials. The bumpers are designed with safety features since it is intended to reduce the magnitude of deceleration during the impact. In the design within virtual environment and these are the parts of the bumper model.

A guard is an auto shield made of steel, aluminium, elastic, or plastic that is mounted on the front and back of a traveller auto. At the point when a low speed crash happens, the guard framework assimilates the stun to avoid or diminish harm to the auto. A few guards utilize vitality safeguards or sections and others are made with a froth padding material. The auto guard is intended to counteract or decrease physical harm to the front and backsides of 
traveller engine vehicles in low-speed crashes. Car guards are not normally intended to be auxiliary segments that would altogether add to vehicle crashworthiness or tenant insurance amid front or back impacts. It isn't a security highlight planned to counteract or moderate damage seriousness to inhabitants in the traveller autos. Guards are intended to ensure the hood, trunk, grille, fuel, fumes and cooling framework and also security related hardware, for example, stopping lights, headlamps and taillights in low speed impacts.

\section{Optimization of Bumper Systems}

The improvement of passive safety with simultaneous consideration of the aspect of light weight construction plays an outstanding role. In front- and rear impacts as well as accidents with pedestrians, the bumper systems, consisting of the outer shell, cross bars and energy absorbing elements, have a special importance. The requirements vary thereby between:

- Pedestrian Accident: Protection of the pedestrian during the impact with the vehicle by preferably large outer skin panels with rounded impact zones.

- Crash Repair Test: Protection of the body by exchangeable energy absorbing elements in the lower velocity area

- Passenger Safety: Equal dispersion of the occurring forces into the whole structure to conserve the survival space of the passengers with high impact velocities.

\section{Methods of Bumper Testing}

The front bumper is the part, during a front crash that has contact with the opponent vehicle. The structural requirements of the bumper are very multifaceted. In component tests at the drop tower facility or in the crash test facility, which reflect different crash repair tests, flexural rigidity of the bumper as well as the deformation force level of the absorption elements can be determined. On servo-hydraulic test benches these tests can be accomplished quasistatically.

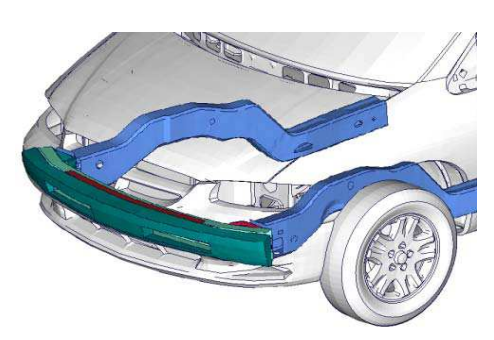

Figure 1: Front Bumper

\section{FORMULATION OF STRUCTURAL ELEMENTS}

The idea of geometry and removal interjections that have been utilized in the plan of two-and 3-D continuum components can likewise be utilized in the assessment of bar, plate and shell basic component lattices. In any case, where as in the definition of the continuum components the uprooting $\mathrm{u}, \mathrm{v}, \mathrm{w}$ (whichever are relevant) are inserted as far as nodal point relocation of a similar kind, in the plan of auxiliary components, the removals, $\mathrm{u}, \mathrm{v}$, and $\mathrm{w}$ are interjected as far as mid-surface dislodging and turns. This procedure corresponds in essence to a continuum isoparametric element formulation with displacement constraints. In addition, there is of course the major assumption that the stress normal to the mid surface is zero. The structural elements are for these reasons appropriately called degenerate isoparametric elements, but frequently still referred them simply as isoparametric elements. 


\section{OBJECTIVES}

The aim of this work is to study front bumper of one of the existing passenger cars in Indian market and suggest design Improvement in front bumper of a passenger car, in terms of material selection using Impact Analysis.

- $\quad$ To perform the Impact Test on 2 variable designs.

- $\quad$ Build the FE model as per the cad and perform impact test using a barrier.

- And find out the energies, stress and displacements for an Assumed high-strength sheet molding compound (SMC).

\section{LOW SPEED IMPACT TEST}

(Solver: LS - Dyna)

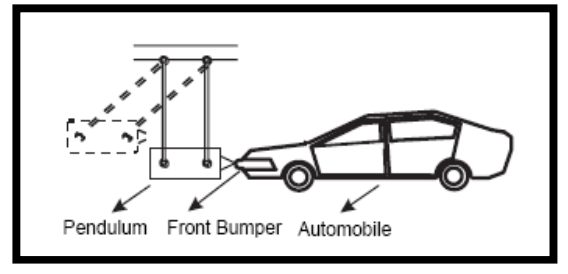

Figure 2: Impact Test

\section{FINITE ELEMENT MODEL}

Vehicle CG (Mass of 1.435 tones is assumed.)

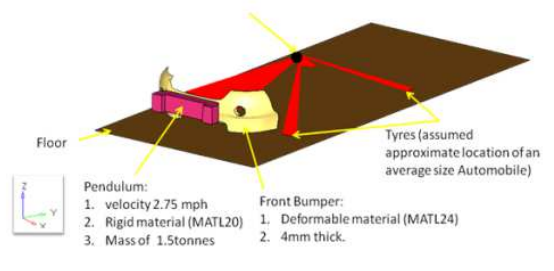

Figure 3: Fem Model of Bumper

All the assumptions were made from average weight automobile passenger vehicle, to have appropriate results (deformation \& Stresses) in bumper and beam. Next slides give brief regarding material properties.

\section{FRONT BUMPER FE MODELING}

- Modeling has been done based on the component:

- $\quad$ Bumper is modeled with shell elements

- Element formulation - 16 as per L-S dyna which is also known as fully integrated shell element.

- $\quad$ And number of integration points for shell used is 3 .

- Shear correction factor which scales the transverse shear stress is recommended by as $5 / 6$ or 0.833 ).

- And remaining all components is assumed to be rigid components and the vehicle has been represented with mass lumped at CG of the vehicle, using RBE2 element as connection between bumper and mass. 


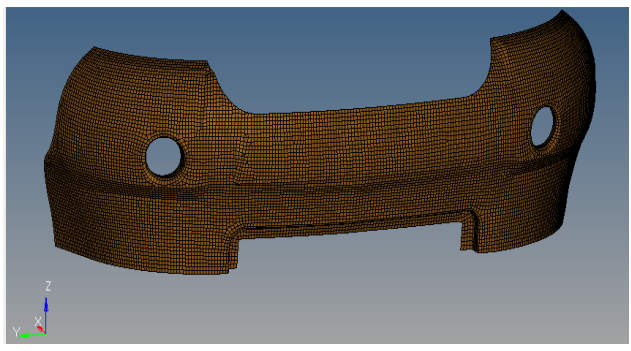

Figure 4: Mesh Model of Front Bumper

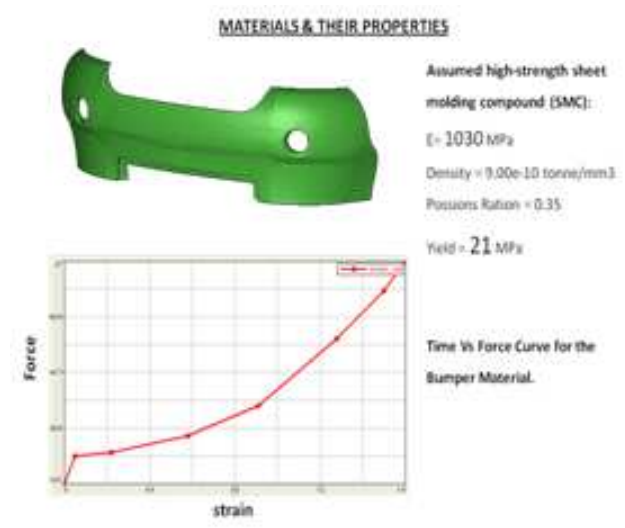

Figure 5: Material Specifications of Front Bumper

Pendutum and foor were rigid, so Martzo (comtrainetinal DOFy)

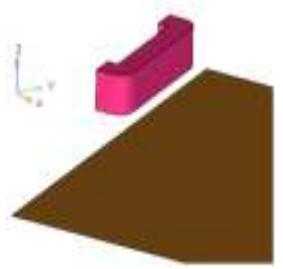

Since the pendulum as to oscillate in a particular direction, it has been constrained in particular direction.

\section{Loading Conditions}

A velocity of $2.75 \mathrm{miles} / \mathrm{hr}$ is used as an initial velocity on the nodes of barrier towards the vehicle direction. (Time-0.05Sec or 50 milli-seconds)

An output has been requested for a node on the pendulum and a node at the CG of the vehicle to extract the mean deflections along the time span.

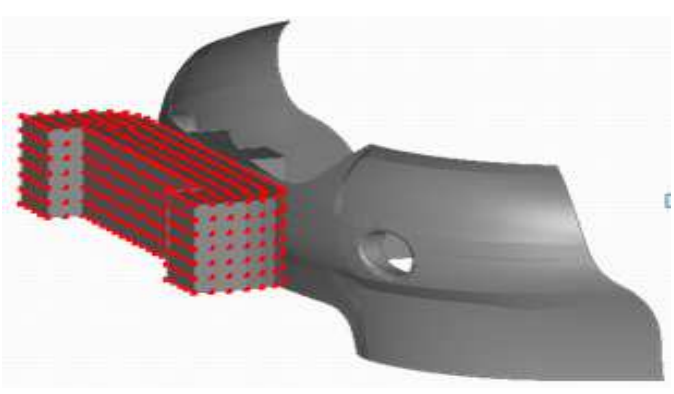

Figure 6: Loading of Front Bumper 


\section{RESULTS}

\section{Plastic Strain in Beam Only}

Bumper Design 1

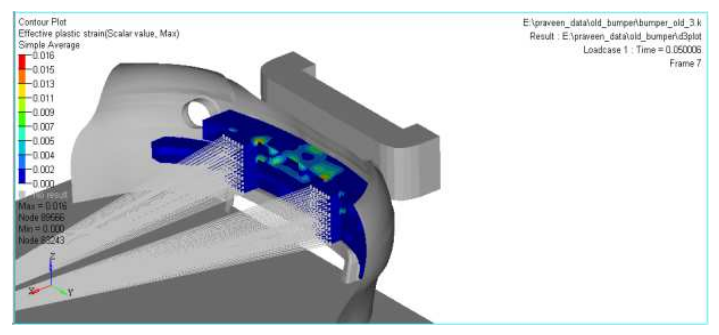

Figure 7: Strain Result of Front Bumper

\section{Bumper Design 2}

\section{(Optimized)}

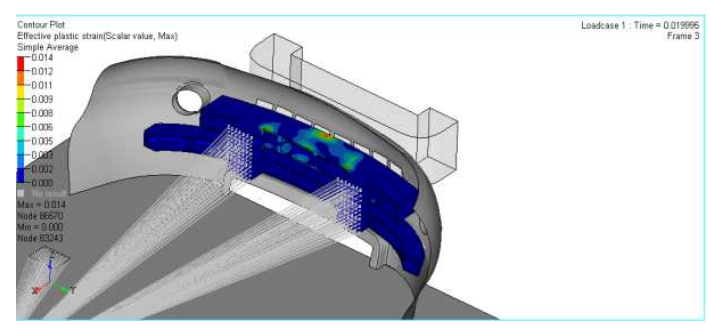

Figure 8: Strain Result of Second Design

Comparing the both designs, second design (optimized) is considerably having less plastic strain and less mass.

\section{Stresses in Bumper}

Bumper Design 1

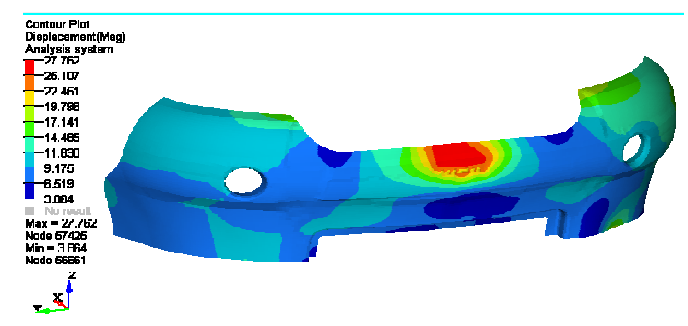

Figure 9: Stress of First Design

Bumper Design 2

(Optimized)

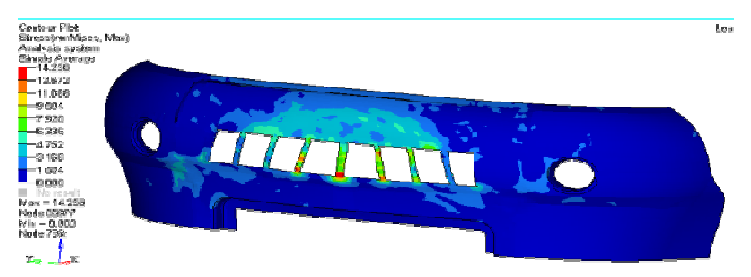

Figure 10: Stress of Second Design

Comparing the both designs, second design (optimized) is considerably having less stress. 


\section{Stresses in Beam}

\section{Bumper Design 1}

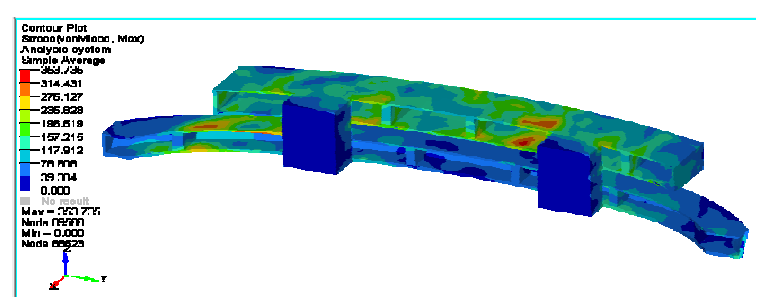

Figure 11: Stress of First Beam

\section{Bumper Design 2}

(Optimized)

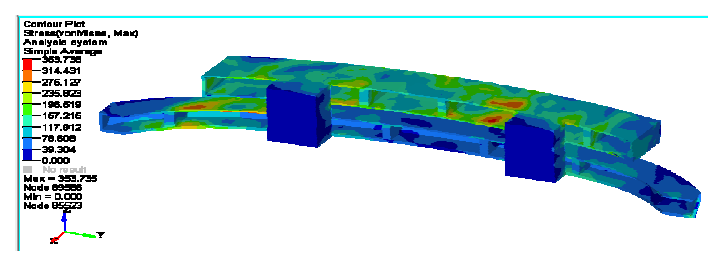

Figure 12: Stress of Second Beam

Comparing the both designs, second design (optimized) is absorbing more loads because of bumper with removed material. And, as per the assumed material for beam, stresses are near to yield.

Table 1: Comparison of Results

\begin{tabular}{|l|l|l|l|}
\hline Material & Von-Mises Stress & Deflection & Strain Energy \\
\hline Structural Steel & $39.97 \mathrm{Mpa}$ & $0.1946 \mathrm{~mm}$ & $8.102 \mathrm{~J}$ \\
\hline Polyethylene & $41.258 \mathrm{Mpa}$ & $33.938 \mathrm{~mm}$ & $1416.2 \mathrm{~J}$ \\
\hline
\end{tabular}

\section{CONCLUSIONS}

Comparing the both designs, second material design (optimized) is absorbing more loads, because of bumper with removed material. And, as per the assumed material for beam, stresses are near to yield. Polyethylene has good chemical resistance. Two sorts of guards are utilized; low thickness polyethylene (LDPE) and high thickness polyethylene (HDPE) can be made in a scope of densities. Application: glass fortified for auto bodies, electrical protection and bundling, where quality and feel are critical.

\section{REFERENCES}

1. Hosseinzadeh RM, Shokrieh M, and Lessard LB, "Parametric study of automotive composite bumper beams subjected to lowvelocity impacts”, J. Composite Struct, 68 (2005):419-427.

2. Marzbanrad JM, Alijanpour M, and Kiasat MS, "Design and analysis of automotive bumper beam in low speed frontal crashes”, Thin Walled Struct, 47 (2009): 902- 911.

3. Mohapatra S, "Rapid Design Solutions for Automotive Bumper Energy Absorbers using Morphing Technique”, Altair CAE users Conference 2005, Bangalore, India.

4. Andersson R, Schedin E, Magnusson C, Ocklund J, "The Applicability of Stainless Steel for Crash Absorbing Components", SAE Technical Paper, 2002. 
5. Butler M, Wycech J, Parfitt J, and Tan E, “Using Terocore Brand Structural Foam to Improve Bumper Beam Design”, SAE Technical Paper, 2002,

6. Padmanabin Gopalakrishna \& Gangavarapu Kiran Kumar, A Proposal on High Speed Pipelined Multiplier Architecture, International Journal of Semiconductor Science \& Technology (IJSST), Volume 5, Issue 4, November-December 2015, pp. $19-28$

7. Carley ME, Sharma AK, Mallela V, "Advancements in expanded polypropylene foam energy management for bumper systems”, SAE Technical Paper, 2004.

8. Witteman WJ, "Improved Vehicle Crashworthiness Design by Control of the Energy Absorption for Different Collision Situations”, Doctoral dissertation, Eindhoven University of Technology, 2000. 
